\title{
Public Space, Infrastructure, Landscape: an interdisciplinary matrix for urban spatial continuity
} Ana Luísa Brandão, Pedro Brandão Universidade de Lisboa, CERIS - Civil Engineering Research and Innovation for Sustainability, Portugal Universitat de Barcelona, POLIS Research Centre, Facultat de Belles Arts, Spain ana.luisa.brandao@tecnico.ulisboa.pt | pedro.s.brandao@tecnico.ulisboa.pt

\begin{abstract}
Spatial growth of cities corresponded to new theoretical and practical knowledge capacities with new kinds of urban infrastructures, new services organisation and new construction methods, of XIX and most of XX century's industrial space production. The decline of those capacities and a "crisis" of modern models, followed by the still on-going post-industrial transition process of the past 50 years are translated in many different forms of spatial, social, economic and cultural organisation and diversity of emerging urban contexts. Contemporary processes seem to carry difficulties in understanding and conducting urban transformation in such diverse and changing context. What strategic elements can be used to interpret and act in such contexts? In this paper we intend to show an interdisciplinary perspective of public space as part of strategic and theoretical principles recognised by several fields of urban knowledge and practice: we include the spatial continuity of the Commons in those structuring principles, as a notion of urban "publicness". These new perspectives require a perception of public space that goes beyond traditional city references, to other peripheral or scattered urban areas, but maintaining its fundamental structuring role, as systemic and interactive reference for complex urban environments. Through a study on the specific case of the South Bank of Lisbon Metropolitan Area, we present a conceptual operative matrix, based on the hypothesis of strategic interaction between urban systems, aiming for its structuring potential for spatial continuity - public space, infrastructure and landscape.

Outputs of this study aim at a contribution to a more flexible and interactive structuring approach to urban design and planning, focused on interdisciplinary perspectives of public space production.
\end{abstract}

Keywords: public space; infrastructure; landscape; interdisciplinary; spatial continuity.

\section{To cite this article:}

Brandão A. L. and Brandão P. (2017). Public Space, Infrastructure, Landscape: an interdisciplinary matrix for urban spatial continuity, The Journal of Public Space, 2(I), I23-I34, DOI: I0.5204/jps.v2il.55

This article has been peer-reviewed and accepted for publication in The Journal of Public Space. Please see the Editorial Policies under the 'About' section of the journal website for further information. 


\section{Introduction}

Although 'industrial city' is understood as the result of urban expansion and city reorganisation related to industrial production models (critically portrayed by Engels and other social European thinkers in the 19th century), the first use of the term "industrial city" was perhaps made by Tony Garnier, in 1905 (Choay, 1965). Before that, "Urbanization" concept had already been used by Cerdà in the Teoría General de la Urbanización (Cerdà, 1867) as the theoretical and practical knowledge about the city's new production system, with new features of urban infrastructure, facilities, energy, transportation or housing development. Cities growth was associated with new kinds of production tools organised in plans.

The breakdown of the industrial model followed by post-industrial transition corresponds to diversifications and specialisations of urban knowledge, developed by several scientific areas, design and planning disciplines. On one hand this specialisation corresponds to a deepening of sectorial knowledge (e.g. mobility, environment, social sciences, engineering, economy, etc.), but on the other hand, no longer responding to the complexity of diverse urban phenomena where less predictability and greater uncertainty are now dominant. After I 50 years of beliefs, experiments and models, this knowledge no longer seems effective to solve emerging problems in many of present urban contexts.

In such a changing and diverse period, what kinds of urban knowledge are available? Different situations, perspectives and dynamics in several realities could still be expected to work with a same stable and independent disciplinary practical and theoretical knowledge base? The unstable variable contexts and characteristics of post-industrial cities have to be understood as a large variety of urban realities and a requirement for collaborative and reflexive practice of a variety of knowledge cultures referring to the contemporary city. So instead of one paradigmatic model, of one knowledge base responding everywhere to same needs of urban space production, some reflexive action needs to be taken on what we call urbanism or city planning.

\section{New post-industrial territories and 'commons' systems - a case-study}

The transition from what we call the industrial city to a diverse set of different urban realities we live in today, may adopt a great variety of what might be called 'post-industrial urban metropolis' (Bell, 1973) including a new scale of urban space production (Lefebvre, 1974). At the least we may agree considering that today there is a much less homogeneous and a more diverse, extensive and scattered urban reality, which lacks a uniform urban identity. What we generically call post-industrial (other authors refer to it as "post-modern") is in itself illustrative of the complexity of transition we deal with (A. Brandão \& P. Brandão, 2013).

The same observation can be made to public spaces of contemporary cities (Carmona, $2010 a$ ). New perspectives require the perception of public space to move from a feature of urban life based on traditional city spatial references and to start being understood in the context of contemporary urban complex changes: increasing mobility and social and economic connectivity, new typologies (24h spaces, multifunctional spaces, ...) and characteristics (more heterogeneous and conflicting, subject to commodification processes, ...). Public space production is no longer restricted to traditional models of public space - i.e. the square, the garden - in typically dense and central urban environments. Instead public space is embedded in those contemporary urban dynamics 
also facing its related issues, as lack of connectivity, segregation, loss of activities and social interaction.

If industrial city models were marked by long-term ideas and convictions enabling its planning, contemporary stresses the logic of real time and short term horizon to many resources. Recent worldwide changes lead us to a "cityness" process notion encompassing different ways of urban being, with different spatial imprints from what we were used to call a "city" (Choay, 1994).

Interdisciplinary experimentation isn't a "normal" practice but when diverse realities develop in uncertain contexts, shouldn't we focus on "common thinking”, valuing reflexive concepts and collaborative interaction? More effective concepts are now required to respond to emerging public investment targets, at new range scales and types of urban space systems with new thematic interrelations.

The hypothesis to be placed is that persistent and common values can act as interdisciplinary referents (with combined tools and concepts) encompassing complex changing realities and transition periods. In that sense, our hypothesis is based on urban spatial continuity as a conceptual integration reference of common and persistent spatial service value: where public space (interaction, sharing and identity capacities) interacts with other urban systems - infrastructure (mobility facilitator, urban activities support) and landscape (life production potential, ecological sustain).

Therefore public space should be considered, not as a sum of isolated space types, but as a network of places (Pinto \& Remesar, 2012) with shared set of properties, interdependences and interactions, in a systemic perspective, fostered by functional and morphological sense. New multidimensional facts under the theoretical principle of urban space continuity in space and time, may answer to present dilemmas: growth of scale and distance (dispersion); growth of complexity and diversity (indeterminacy) and growth of non-systemic actions (disruption) in today's city call for more integration of a system of public spaces at the centre of urban transformation processes (Pinto \& Brandão, 2015). A conceptual and operational matrix aims to interpret these spaces in unstable, disconnected, or unforeseen contexts, by mapping urban qualities focusing on the basis of urban spatial continuity, and testing urban systems with structuring potential.
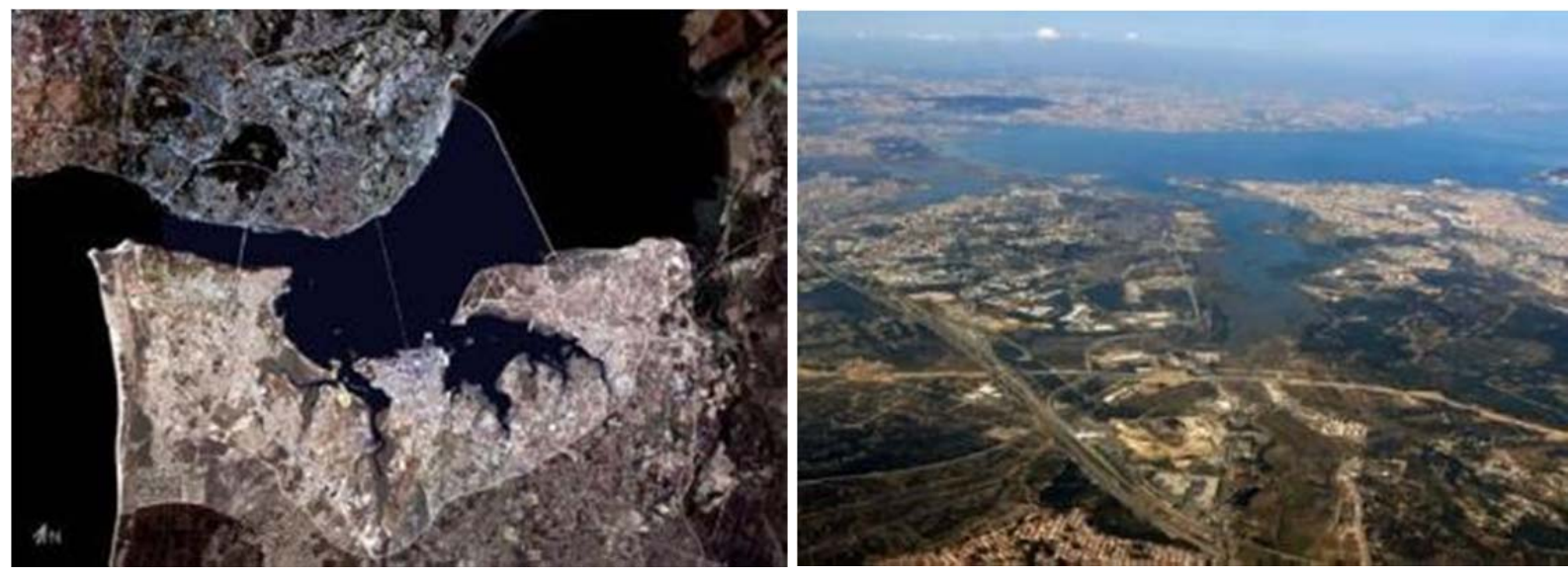

Fig. I. South Bank in Lisbon Metropolitan Area. (A) orthophotomap and (B) aerial view. Source: (A) base imagery source Google 2010 and (B) Remesar A. 2012 
By mapping spatial service values, potential for their interaction and integration becomes legible as a new coherent structure of the 'Commons', acting as a reference in transition process, managing uncertainty and balancing changing needs, actors roles and resources.

Discontinuity and indeterminacy on Lisbon Metropolitan Area Tagus South Bank.

Formulation of an "Industrial city" in Portugal comes only on early $20^{\text {th }}$ century, also translating a late industrial structure of economy and territory. Tagus South Bank as part of "Lisbon industrial belt" is still not a homogeneous urban area (Fig. I). It is characterised by contrasting realities and mixed patterns of growth and decay. In the growing of industrialisation process, as well as in "post-industrial" transformations, despite the existence of planning policies, rules and operational tools along different periods, it is possible to find several unstable and uncertain aspects, examples of prevision or decision incapacities, and ambiguities.

A brief presentation of some transformation episodes allow us to show several aspects of discontinuity and indeterminacy in urban process, emphasizing the need for new understanding of a Commons' system structuring potential:

a) Only at the beginning of $20^{\text {th }}$ century, the biggest industrial centre of Portugal was born in the village of Barreiro driven by the combination of prime location and infrastructure (port and railway network). The growth in industrial activity goes together with increasing population and urban sprawl beyond the limits of the village, in a continuous urban-industrial axis. In the absence of urban planning practice, initial growth appears informally and supported by services provided by the industry itself. The decay of this industrial model since the 1970s, fails to address the deficits of infrastructure and facilities, lack of urban qualities and important environmental liabilities. But facing the decay of industrial activity we can find a new "urban production driving force" by replacement or else by diversifying city activities?

b) The tourism potential of the South Bank has undergone various visions and models: a futuristic city, a garden city of individual houses, a natural park for recreational activities, mass tourism developments, inter alia. Tourism is the subject of regeneration operations, while the riparian areas of the estuary recover slowly from intense industrial use. However, the 60's land occupation with forest consumption for illegal allotments, and later tourism products such as golf courses, small resorts, favoured gated communities, in disconnected developments based on natural features of the area, which normative planning unsuccessfully attempted to control and recent planning strategies try to minimise. How can we take advantage from the inherent potential, promoting diversity and complementarities, without degrading natural ecosystems?

c) The first bridge connection in the 1960's led the development of a Regional Plan, given the need to control urban sprawl. Urban and population growth driven by industry (in its heyday) overlaps what was spurred by easy accessibility to Lisbon. The plan had no operative capacity (legal or financial) to conduct or arrange urbanisation when unplanned transformations were already ongoing. Populations sought answers to their needs through illegal urban space production with large deficits of infra-structuring and facilities. If a plan did not secure the execution of its options, neither the absence of other plans prevented occupation of large extensions, which should be the critical tool to restructure urbanisation? 
d) In the 1990's a second bridge was built to reinforce national and metropolitan accessibility system, but the location decision was untied to regional planning options. The connection transformed the metropolitan structure and relations: new accessibility reoriented urban and population growth to a more polycentric model, favouring less urbanised territories. Later, planning instruments supported urban expansion - residential schemes, logistic areas, commercial spaces, etc. - but lacked scheduled programming actions of urban design. Near road accesses expanding urban perimeters, generated new fragments and voids. Could occupation flexibility over time be balanced with structuring elements of urban relation?
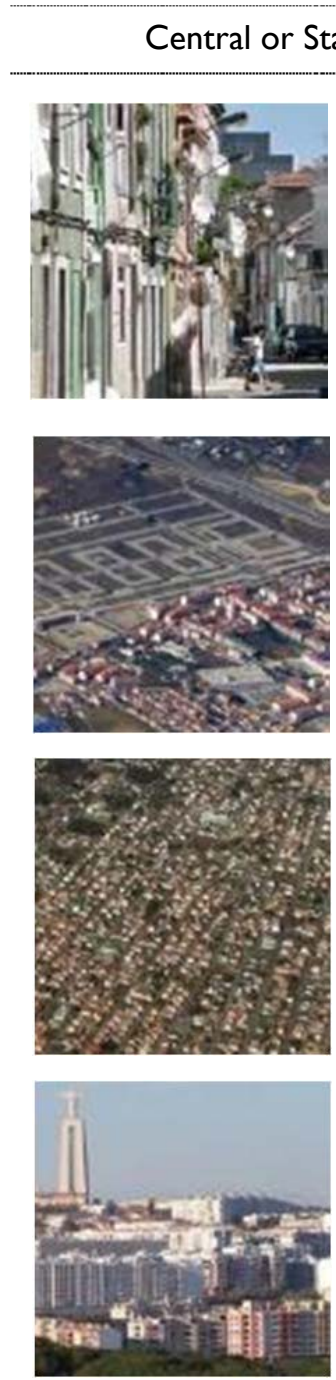

Historic areas with issues of preservation and ageing, searching for population and activities diversification while managing heritage features for tourist attraction.

Urban voids or fringe areas seek compatibility between new activities and old surroundings, by managing transition or temporary solutions.

Mono functional spaces with deficits of urban spatial quality, urban infrastructure and facilities pondering key investment for diverse possibilities.

Housing areas, residential neighbourhoods in need of "liveable" amenities, by joining communities into a cohesive and lasting identity.
Peripheral or transforming spaces

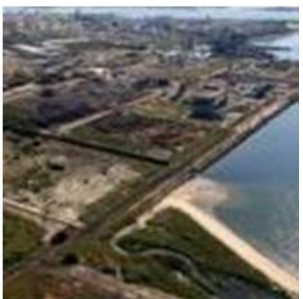

Derelict or brownfield areas with lack of activities and investments, but with large availability of land for new possibilities and identities.

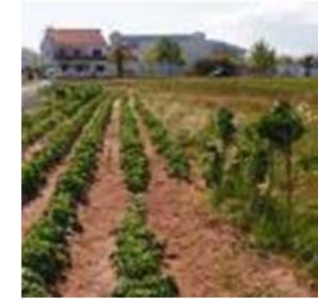

Peri-urban changing areas responding to present population needs for facilities and balancing urban and nature evolving dynamics.

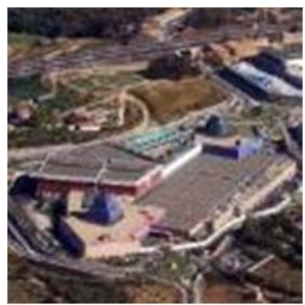

Hubs, poles and nodes in large accessibility and strategic development areas, requiring a set of elements both for global attraction and local scale features

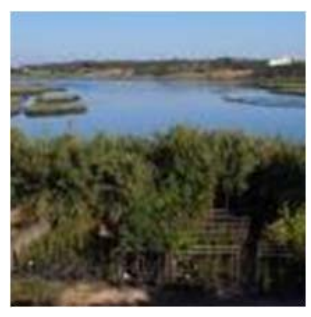

Landscape features in urban areas, managing leisure and productive activities (e.g. by fishing, orchards, food gardening) in sustainable ecosystems, while saving reserve spaces.

Tab. I. Examples of urban instability indicators in the South Bank area.

Source: Adapted from A. Brandão, 2013.

e) In late 2000's the possibility of an important set of infra-structure initiatives - new Lisbon airport, new bridge connections, high-speed railway line and logistics platform created great expectations for this area's development. Related planning processes were launched, including a large development operation on former industrial areas on the riverfront. The model followed Lisbon's EXPO98 World Exhibition project. 
However, in a larger peripheral area, with no triggering event to prompt change and in a different economic, financial and political context the infrastructure projects set on hold. The absence of a leverage of public investment due to global financial crisis compromised the entire development operation. Is uncertainty due to external context or was it an effect of short adaptability of the proposed model? As result of rapid and uncontrolled urban expansion, many spaces are characterised by disconnected parts or poorly designed public spaces, similarly to several south European urban change processes. Urban change problematic as an adaptation flexible process is in the need for new approaches, which can restore public space quality.

\section{Spatial continuity matrix of the Commons: public space, infrastructure, landscape}

An interdisciplinary theoretical principle

The diversity of urban fabrics and related problems is also translated to the production of public spaces: "What is clear is that contemporary trends in public space design and management are resulting (over time) in an increasingly complex range of public space types" (Carmona, 20 I0b: 172). Our question is about a strategic necessity: with what instruments can we act in a growing, diverse, complex territory, in changing conditions? What is the Commons role in a structuring process of "becoming urban"?

Knowledge on the city no longer reflects the diversity of problems in a variety of contemporary urban environments when it is structured top-down from mechanical rational principles and tools defined for industrial mode of production. In fact city knowledge by organising principles, rules, procedures and former planning practices now report difficulties in mastering present urban phenomenon.

Our proposal for an operative matrix, is based on urban structuring elements needed in emerging urban areas, as an approach to common concepts of urban space continuity, as a transversal and interacting concept, crossing several urban dimensions (Carmona, Heath, Oc, \& Tiesdell, 2003): morphologic, experiential, economic, social, political... with an interdisciplinary and systemic perspective. For the moment there are no previously agreed starting points, based on alleged ability to predict and master variables on this perspective ${ }^{2}$. Thus, it is essential to question "disciplinary plots and fences" regarding urban approaches in planning, urban design, infrastructure, architecture, landscape, transportation, art, social organization, economics, history, geography, etc. Interdisciplinary experimentation of a "crossing" principle such as spatial continuity is not yet a common practice. But there are some positive exemplary cases such as the recognised need to match the quality of mobility with spatial quality showing what can be done:

a) by experimenting new types of joint infrastructure and public space in "shared space" projects (Monderman, 2007),

b) in regenerating transport interchange concepts by integrating mixed uses and services in inter-modality areas.

c) in experimenting new forms of urban systems integration - namely public space, landscape and infrastructure in urban actions risk preventing of climate change effects.

A conceptual and operational matrix, will aim to interpret these spaces and give them better urban representation in different readings by focusing on structuring urban spatial 
continuity by a procedural logic - upgrading of the Commons role, and systems service integration. For that we propose a reflection on matrix application to urban spatialtemporal adaptability promotion.

Urban systems for urban continuity: Public Space, Infrastructure, Landscape

Although public investment and public attention on urban design projects grew much in recent years, many actions still focus on isolated units or local actions, often lacking connectivity or integration, so as to gain real meaning as urban systems and to provide more social and economic value return, ensuring sustainability.

We now acknowledge weak returns in quantity and quality of use, economic activity attraction, long term social meaning, basic utility or environmental evidence as public spaces that are often due to poor network qualities. This means there is a systemic potential that needs to be assessed and fostered, so as to enable spatial and functional continuity in fractured urban fabrics. Therefore a research based on a combined action "systems of collective spaces grounded in the interaction with landscape and infrastructural systems" (Portas, 2004) can frame methods and tools appropriate for specific contexts.

Such features are also the more lasting elements of urban fabric, defining public interaction, with ability to support and structure transformation over time, securing conditions for later decisions related to opportunity, resources availability, stakeholders interests.

Common and persistent values of public space (interaction, sharing and identity capacities), interacting with infrastructure (mobility facilitator, urban activity support) and landscape (production potential, ecological sustain), are the base for management strategies.

PUBLIC SPACE can be characterized as urban space for common use, with no restriction to access, in opposition to private use of public interest space. Public space is a structuring layer of urban form (space between buildings), which can be seen as hardware, performing territorial and functional integration in the city. But as software (P. Brandão, 2008) it incorporates relations and interactions that make urban life - a social-cultural dimension, representing its society or community, as a space for expression and sharing (Borja \& Muxí, 2003). In contemporary city, public space is no longer made only by canonical typologies - square, garden, public, private - but evolves several hybrid spaces and joint uses, including the sphere of communication and virtual spaces. To understand its complexity we need to focus on systemic views, a network space (Pinto \& Remesar, 2012), fostering functional and morphological continuity.

INFRASTRUCTURE can be defined as the system - the set of elements - that frame and support urban life and structures. As the backbone of transformation, infrastructure is one of the more lasting elements of built environment, visible at an initial phase and building on throughout time, supporting several cycles of transformation (Lukez, 2007). In today's city, exchanges, flows, connections, are important features and can sometimes be and alternative (or substitution) to traditional social and urban relations (Ascher, 1995). In addition to physical structures, other networks of technological or virtual links add new interaction possibilities. Expansion of infrastructure networks changed territory' space uses. But the potential of network connections is also in their capacity for multi-mobility 
and communications, as infrastructures in a networked city use all possible links and mediums to be connected.

LANDSCAPE can be seen as a complex and dynamic system, including natural and cultural interacting aspects, changing over time. Traditionally based on physical, biological, natural objectives it also is an expression of human activities. Today, the landscape concept is expanding, as result of interdisciplinary action, with combination of cultural, natural and environmental problematic ${ }^{3}$. Its holistic character is referred as a base for an integrated territorial management (Cancela d'Abreu, Correia, \& Oliveira, 2004) for its "expression of numerous relations throughout time between natural and human factor of a certain area". A dynamic system, in constant change and reinterpretation (Antrop, 2005), but capable of support a community identity, conducting it through transformations. Although the "root" of landscape is located in natural life supporting systems, in post-industrial cities, urban landscape is also characterised by urban built-up continuous, with urban-rural distinctions blurred in new hybrid categories.

The broader set of "public use spaces" is now more inclusive, embracing a greater variety of users. It is also structuring connection and continuity, allowing a management of different timeframes of movement and transformation. Spatial continuity of living spaces, show itself in different scales and ways of space appropriation - from the street and neighborhood to the larger spaces of encounter and interaction, we can assume that space networks - integrating landscapes, infrastructures or public spaces - add up as interconnected systems, i.e. part of each other acting for converging objectives. Integration of these concepts in a spatial continuity matrix has to respond to an interdisciplinary culture opposed to the limitation of "spatial expertise" and ignoring identified dimensions, and denying the need for broader, transversal strategies.

Signs of continuity and discontinuity in metropolitan structure In recent years, Lisbon South Bank spaces have been targeted with various urban regeneration strategies with different aims and results. The majority of these actions fostered the creation of new public spaces - more diverse typologies than the traditional central ones - with potential to create a wider network of spaces and relations. Based on some of these examples, we intend to map the continuity matrix, with potential for articulating the territory's complexity and diversity.

a) In an important touristic area, the project of a new cycle path (Fig. 2) connects the ferry terminal on the traditional fisherman village Trafaria with the main urban seaside of Caparica. The path follows the existent urban structure, using street or road connections and integrating ongoing regenerations actions. Urban fabrics connected by the path are very diverse - informal settlements, high-density housing, single-dwellings - and correspond to different typologies of public spaces and uses - squares, urban parks, recreational natural areas, beaches, avenues, poorly designed streets. As a result, the cycle path comprises different sections and designs, but ensuring connectivity and continuity, providing a space for recreational activities but also social interaction. As an infrastructure element the cycle path connects to other transport modes and networks (ferry boat, bus), extending links to Lisbon and beach areas. The linear and "light" characteristic of this structure allows its future expansion to connect other areas and transport modes. Connection also comprises important natural protected spaces, 
(agricultural areas, coastal dunes and forest areas), linking and providing a systemic integration of natural features.

The relative "lighter, quicker, cheaper" way of developing a connection like this can be used to create a network of further connections fostering public uses and active modes of transportation, that may be diversified and complemented by adding elements from other transports, natural and social systems, connecting other proximity realities.
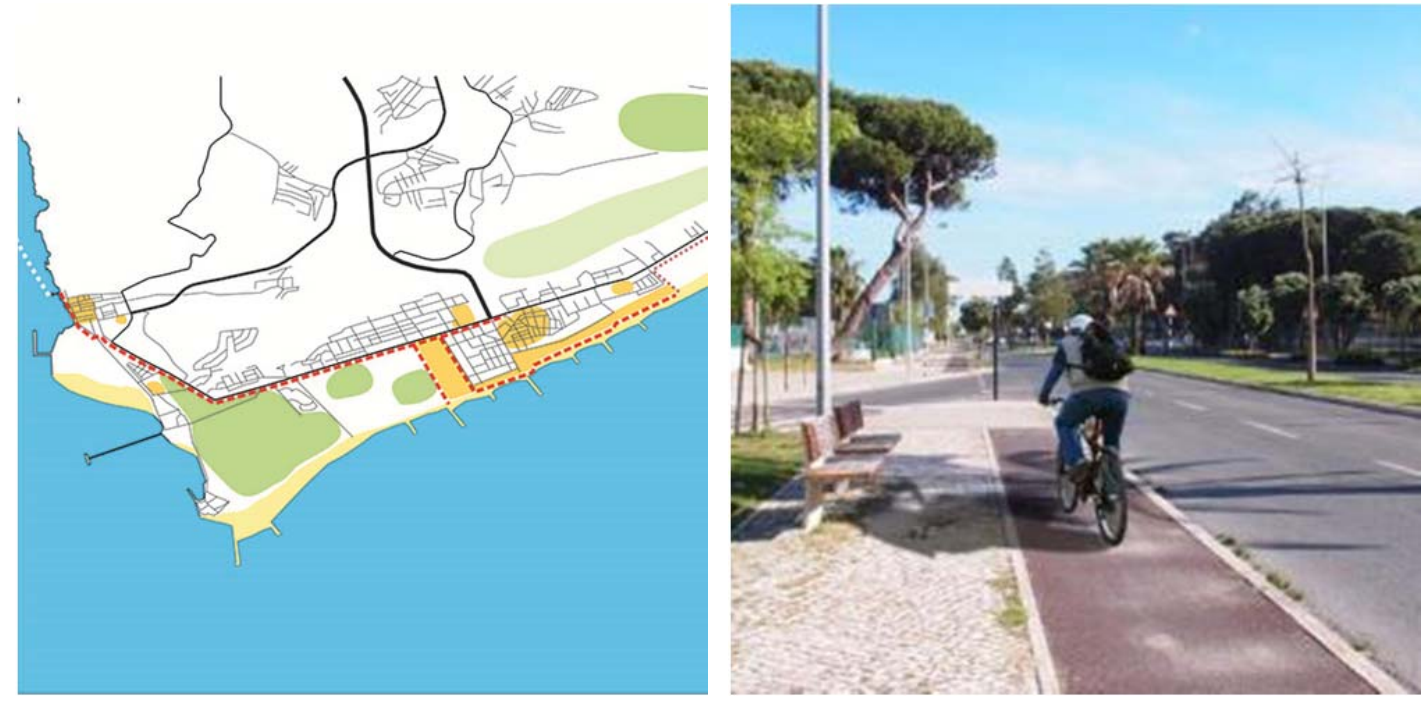

Fig. 2. Trafaria-Caparica cycle path connection (A) mapping uses and connections; $(B)$ avenue insertion view. Source: $(A)$ and $(B)$ Brandão $A .2014$.
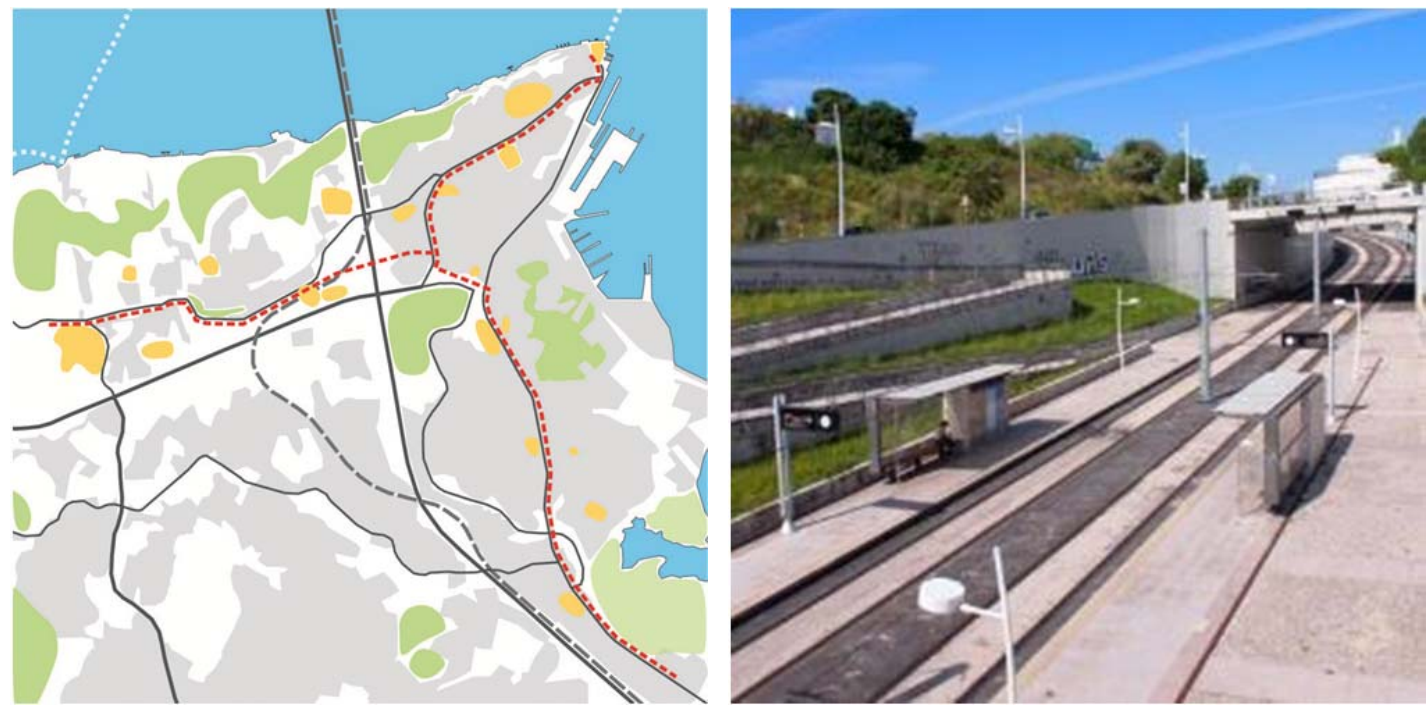

Fig. 3. Light rail transit (A) mapping connections and urban spaces; (B) station with poor urban insertion. Source: (A) and (B) Brandão A. 2014.

b) Developed to link the main urban nucleus of the riverside area, a light rail transit network (Fig. 3) aims to surpass the deficits in the mobility systems. Financial and operational constrains limit the network to Almada municipality connecting the city centre, other centrality areas and transport hubs through a diversified urban structure. Strong urban growth followed disconnected and individual developments with few 
connection or complementary strategies. The light rail transit implementation has redesigned some parts of fragmented urban structure with new articulation axis and easier connections patterns, but also disrupted previous continuities and urban fabrics, in a "tunnel" type of connection: In some cases transportation system features disregard space quality or possibilities for shared spaces. Natural landscape features along the mobility axis are weak, but some are connected by the transport system.

Major perceptual and image changes made in urban landscape along the system may suggest new interaction possibilities by establishing a strategic development axis improving urban and landscape quality, fostering gradual connections within Almada, by linking several parts and promoting urban mix. Further expansion of the light rail network could extend this continuity to other territories, increasing users and their interactions, focusing on multipurpose links.
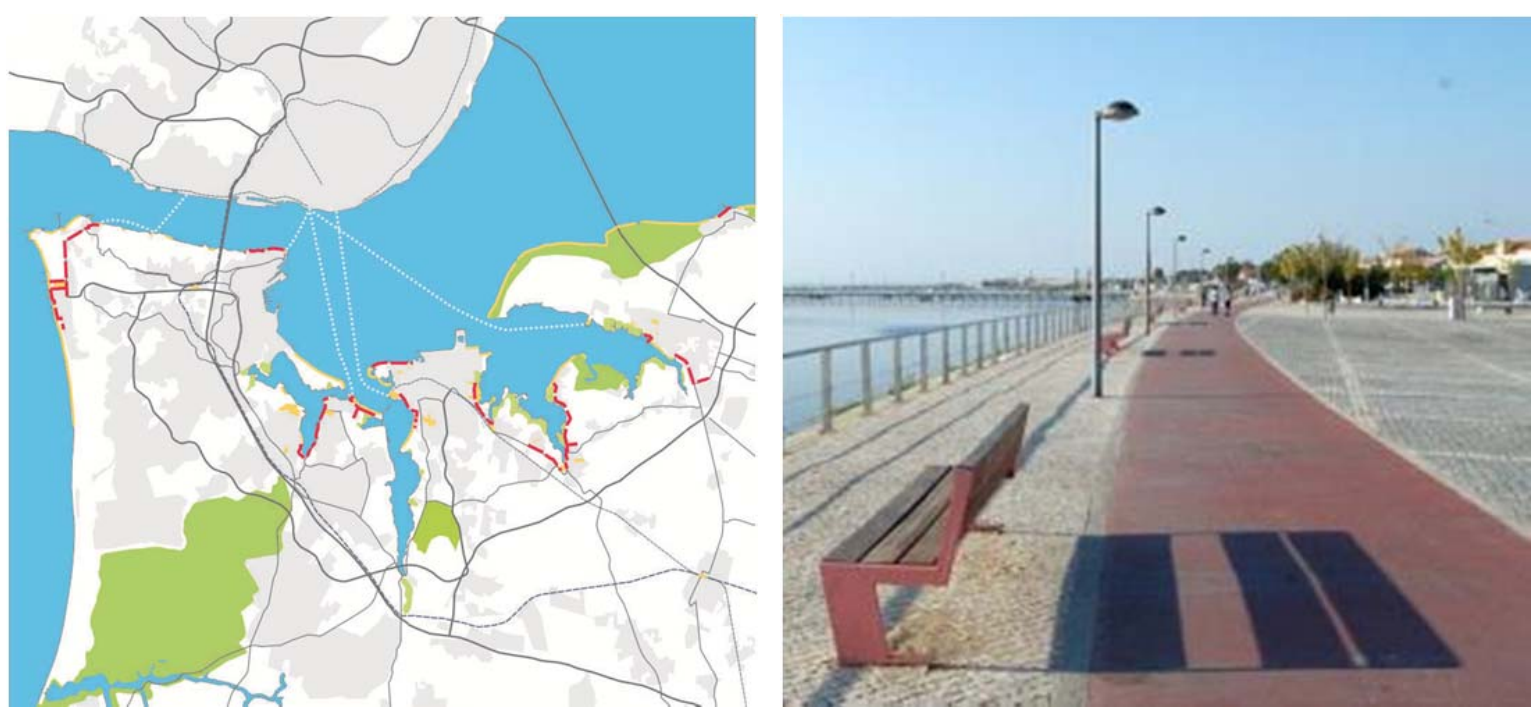

Fig. 4. Waterfront South Bank spaces (A) mapping spaces and connections; $(B)$ urban park view. Source: (A) and (B) Brandão A. 2014.

c) In a wider metropolitan scale, several regenerated waterfront spaces (Fig. 4) already form the base for a relevant linking structure throughout different municipalities, although several expectant spaces remain. Regeneration actions mainly recuperate riverside areas for public space and recreational uses, while supporting local identity features. Although close to historic central areas, many of these structures already surpass these limits providing connection between urban nucleuses. Landscape features are found in the riparian ecosystem (in de-pollution process) and natural spaces in urban parks but also within the inlet's outstanding views and bays. Although these structures are mostly used in recreational activities rather than in daily dislocations, ongoing actions tend to redesign spaces to a less car dependent environment, promoting active modes of transportation by linking to transport hubs.

This existent potential can be further developed. Vacant passive spaces can be used to articulate both regenerated spaces and poorly qualified urban areas, in a network linking all waterfront area. Natural areas, compatible productive uses, passage areas, may ensure a livable landscape. Obviously, new continuous elements cannot substitute other infrastructure or mobility systems, still in deficit for the connection between many of South Bank urban areas. But they can act as a network to both the existent connections 
and future actions, encompassing shared space activities as an opportunity to diversify "typical" waterfront public space initiatives with more productive and social uses, less dependent of large public investments.

These examples of the South Bank area multipurpose spaces, illustrate the potential of sharing systems of public space, infrastructure and landscape to address some questions regarding population's basic needs in a sustainable and interrelated perspective, with spatial quality. Also showing that spatial continuity can be developed in different scales and frameworks (locally, within a municipality or even at metropolitan scale).

\section{Conclusion}

In this paper we addressed a knowledge gap for new interdisciplinary approaches on urban transformation action. The cases analysed showed that different problems and perspectives of post-industrial urban places, where the proposed structuring matrix public space, infrastructure and landscape - can recover urban spatial quality by reestablishing continuity and growing of the Commons' diversity.

Urban Design action should focus on the process of re-structuring urban territories by using Public Space, Landscape and Infrastructure as integrated systems. Mapping the existing structures and available resources, can be a starting point to develop a spatial continuity strategy for common values and spaces, as an interdisciplinary agenda.

The interdisciplinary matrix can contribute to a more flexible and interactive approach to urban design and planning. Further aspects are to be questioned on future investigations. Is it possible to intervene with a "fertilizing" but low intensity action promoting the commons? Can we act in a small and local scale while establishing wider connections by fostering effects and opportunities in a broader urban context?

The use of the matrix analytical interpretation and design practice ensures the articulation of different (spatial) scales, linking different elements to secure the continuity in several layers and keeping the global coherence. Instead of a rigid hierarchy, regulations or restrictions, the coherence between different scales can be secured by reestablishment of connections - as networks of uses, spaces, relations, meanings - through adding and sharing new elements in planning processes, programming and designing does not imply a pre-determined order but rather can be worked on different contexts and solutions. In designing structuring public space elements, priority should be given to the qualities that in the long term can increase their lifecycle, in transversal, diverse and interdependent actions allowing more adaptability options. This systemic perspective enables transition process to be made in incremental steps, instead of replacing or developing drastic transformation actions.

We will find the matrix for Urban Design not in a specific discipline, a specific scope or shape of space, but in the possibilities open by public space as an organising urban system, in interaction with infrastructural and landscape systems, integrating all different and simultaneous "spaces in between" composing the elements of the 'Commons'.

\section{Acknowledgements}

The authors gratefully acknowledge the support of Fundação para a Ciência e a Tecnologia (FCT) under the PhD grant SFRH/BD/699I I/2010 and the research project PTDC/ECMURB/2I62/20I4. 


\section{Notes}

(I) The definition from the Digital Library of the Commons is: "The commons is a general term for shared resources in which each stakeholder has an equal interest".

(2) PSSS - Public Space's Service System is a research project the authors are pursuing in an international and interdisciplinary team between Lisbon, Oporto and Barcelona Universities, developing some of presented intentions.

(3) As a disciplinary concept in some academic traditions (such as in Portugal), Landscape Architecture is connected to a life production process of territorial nature. So landscape as an Urban Design part is less significantly based regarding "image", "skyline" and other visual features and more on eco-systemic concepts.

\section{References}

Antrop, M. (2005). Why landscapes of the past are important for the future. Landscape and Urban Planning, 70(I-2), pp. 2I-34, https://doi.org/I0.1016/j.landurbplan.2003.10.002

Ascher, F. (1995). Métapolis ou l'avenir des villes. Paris: Editions Odile Jacob.

Bell, D. (1973). The Coming Of Post-industrial Society. New York: Basic Books.

Borja, J., \& Muxí, Z. (2003). El espacio público: ciudad y ciudadanía. Barcelona: Electa.

Brandão, A. (2013). The Adaptable City - Urban transformation as a process. Retrieved from http://www.europan-europe.eu/media/default/000I/09/el3 themecontr_36_abrandao_pdf.pdf

Brandão, A., \& Brandão, P. (20/3). Por uma cidade produtiva: a diversidade urbana na transição pósindustrial. Scripta Nova: revista electrónica de geografía y ciencias sociales, 17(446). Retrieved from http://www.ub.edu/geocrit/sn/sn-446.htm

Brandão, P. (2008). O software, o espaço público. Em AAVV (Ed.), Manual de Metodologia e Boas Práticas para a Elaboração de um Plano de Mobilidade Sustentável. Moita. Retrieved from http://issuu.com/dirp.cmmoita/docs/manual tramo

Cancela d'Abreu, A., Correia, T. P., \& Oliveira, R. (2004). Contributos para a identificação e caracterização da paisagem em Portugal Continental. Lisboa: DGOTDU-Direcção Geral do Ordenamento do Território e Desenvolvimento Urbano.

Carmona, M. (2010a). Contemporary Public Space: Critique and Classification, Part One: Critique. Journal of Urban Design, I5(I), pp. I23-148, https://doi.org/I0.1080//357480090343565 I

Carmona, M. (2010b). Contemporary Public Space, Part Two: Classification. Journal of Urban Design, I5(2), Pp. 157-173, https://doi.org//0.1080//357480/003638III

Carmona, M., Heath, T., Oc, T., \& Tiesdell, S. (2003). Public Places - Urban Spaces: A Guide to Urban Design. Oxford; Boston: Architectural Press.

Cerdà, I. (1867). Teoría General de la Urbanización Y aplicación de sus principios y doctrinas a la Reforma y Ensanche de Barcelona (Edición facsímil a cargo del Instituto de Estudios Fiscales, Madrid, 1968). Madrid: Imprenta Española.

Choay, F. (1965). L'urbanisme, utopies et réalités. Paris: Éditions du Seuil.

Choay, F. (1994). Le règne de l'urbain et la mort de la ville. Em J. Dethier (ed.), La Ville. Art et architecture en Europe. 1870-1993, Paris: Centre Pompidou, pp. 26-35.

Lefebvre, H. (1974). La Production de L'espace. Paris: Anthropos.

Lukez, P. (2007). Suburban transformations. New York, NY: Princeton Architectural Press.

Monderman, H. (2007). Designing Shared Space [Mov] (Vol. 7). London: Urban Design London. Retrieved from http://www.urbannous.org.uk/udlhm I.htm

Pinto, A. J., \& Brandão, A. L. (20I5). A multi-scale approach of public space networks in the scattered city. Urban Design International, 20(3), pp. 175-194, https://doi.org/10.1057/udi.2015.4

Pinto, A. J., \& Remesar, A. (2012). Public Space Networks as a Support for Urban Diversity. Open House International, 37(2), pp. I5-23.

Portas, N. (2004). De uma cidade a outra: perspectivas periféricas. Em Os Tempos das Formas (2012) ( la, Vol. II: A Cidade Imperfeita e a Fazer). Guimarães: Escola de Arquitectura da Universidade do Minho. 